\title{
Activation of Subtilisin Carlsberg in Hexane by Lyophilization in the Presence of Fumed Silica
}

\author{
Kerstin Würges**, Peter H. Pfromm ${ }^{\dagger}$, Mary E. Rezac, Peter Czermak** \\ Department of Chemical Engineering, Kansas State University, Manhattan, Kansas, 66506, \\ U.S.A.; **University of Applied Sciences Giessen, Giessen, Germany \\ Published in Journal of Molecular Catalysis B: Enzymatic, volume 34(1-6), page 18 (2005)
}

\begin{abstract}
Subtilisin Carlsberg (SC) was lyophilized from an aqueous buffer solution containing different amounts of unmodified commercial fumed silica. The activity of the enzyme/fumed silica preparation in hexane was compared to pure freeze-dried enzyme, and to a freeze-dried preparation reported in the literature with potassium chloride as additive. A sharp increase in enzyme activity was found to correlate with an increasing amount of fumed silica added to the enzyme solution prior to freeze-drying. A weight-ratio of $98.5 \mathrm{wt} \%$ fumed silica relative to the mass of the final enzyme/fumed silica preparation led to about 130 fold increased activity of SC in hexane (when compared to pure lyophilized SC in hexane). This is about twice the activation effect compared to including potassium chloride in the buffer solution before freeze-drying [1]. When freezing at $-20^{\circ} \mathrm{C}$ instead of in liquid nitrogen, even better activation was observed with fumed silica. We hypothesize that the activation of SC in hexane by immobilization of the enzyme on fumed silica is likely due to the distribution of the enzyme on the large surface area of fumed silica. This alleviates mass transfer limitations.
\end{abstract}

Keywords: fumed silica, activation of subtilisin Carlsberg, immobilization, hexane, lyophilization

$\dagger$ To whom correspondence shall be addressed, Phone 785-532-4312, Fax 785-532-7372, e-mail pfromm@ksu.edu 


\section{Introduction}

So-called "nonaqueous enzymology" has become an important area of research and development [2]. Enzymes exhibit a wide array of novel reactivities and selectivities in non-aqueous solvents. For example, many reactions that are impossible in water due to kinetic or thermodynamic reasons can be performed in organic solvents $[3,4]$ due to the suppression of water-induced side reactions. Improved and altered substrate specificities $[5,6]$ and selectivities can be observed. Examples of practical applications are enantioselective synthesis [7], chiral resolution [8] and combinatorial biocatalysis [9]. The possibility of the solubilization of hydrophobic substrates or products in organic solvents opens opportunities for the enzymatic production of poorly water soluble fine chemicals and pharmaceuticals. The thermal and storage stability of enzymes can be significantly enhanced in nonaqueous media $[2,4,5]$.

One challenge for the use of enzymes in organic media is the decreased catalytic activity which is in general orders of magnitude lower compared to aqueous solution. Several methods to overcome this disadvantage have been investigated. Reversed micelles [10], the immobilization on a variety of materials [11], or surface modification of the enzyme can be employed [12-14]. Immobilization on ceramics was reported for the improvement of enzymatic catalysis at low temperatures [15]. Addition of disodium hydrogenphosphate or L-alanine prior to lyophilization was reported to improve enantioselectivity but not the enzyme activity over native lipase for a reaction in isopropylether [16]. One of the most successful methods to increase the relatively low activity of enzymes in organic media is the addition of inorganic salts before lyophilization of the enzyme [17-19]. The activity of subtilisin Carlsberg (SC) in different organic solvents was increased almost 4000 fold by addition of $98 \mathrm{wt} \%$ of $\mathrm{KCl}$ (relative to the final enzyme preparation mass) to the enzyme in aqueous buffer solution prior to lyophilization [18]. At 
optimum water concentration in the solvent a 27000 fold enhanced activity of SC in hexane compared to the salt-free lyophilized enzyme was reported [1].

The detailed mechanism of this enzyme activation by freeze-drying in presence of $\mathrm{KCl}$ is not entirely clear. It has been hypothesized that the enzyme-bound water (sometimes termed essential water) is the main factor of altered enzyme activity in organic media [20]. This water is thought to provide the enzyme molecule with the internal mobility which is apparently necessary for enzymatic catalysis [4, 20-22]. By adding highly kosmotropic salts prior to freeze-drying aqueous enzyme solutions this essential water is thought to be supplied to the enzyme via the salt $[19,23]$. According to this view, the presence and type of salt would have a significant influence on activation.

We hypothesize here that the low activity of enzymes in organic solvents is mainly due to mass transfer limitations. Since enzymes are not soluble in organic solvents, they will remain in the form of massive "sheets" of protein (see below) that form during freeze-drying of pure enzymes from aqueous buffers. Inorganic salts added, together with rapid pre-freezing in liquid nitrogen $\left(\mathrm{LN}_{2}\right)$ provide a large surface area in form of small salt crystals so that enzymes are finely divided on the surface of the crystals when the salt/enzyme preparation is dispersed in an organic solvent. We show below that salts are not needed to achieve similar or better activation. $\mathrm{LN}_{2}$ pre-freezing can be omitted if a "pre-formed" high surface area material such as fumed silica (FS) is used to immobilize the enzyme. We freeze-dried commercial SC from an aqueous buffer solution containing fumed silica (native particle diameter 7-50 nm). Fumed silica possesses an exceptionally high specific surface area. An activation of the enzyme that can be compared to and sometimes even exceeds that of $\mathrm{KCl}$-activated SC [1] was achieved. Another inorganic high surface area material was also tested with similar results as fumed silica. This supports the 
notion that it is the high surface area and the reduction of mass transfer limitation, not the specific support material that is in large part responsible for the observed activation.

\section{Experimental}

\section{Materials}

SC (EC 3.4.21.14; proteinase from Bacillus licheniformis; specific activity of 8 units/mg solid), fumed silica (purity of $99.8 \%$, specific surface area of $258 \mathrm{~m}^{2} / \mathrm{g}$, particle diameter 7-50 nanometer, as reported by the manufacturer), and nonadecane (puriss. p.a. standard for GC) were obtained from Sigma-Aldrich (St. Louis, MO). Aeroxide ${ }^{\circledR}$ Alu C (spec. surface area: 100 +/- 15 $\mathrm{m}^{2} / \mathrm{g}$ ) was obtained as a sample from Degussa Corporation (Parsippany, NJ). N-acetyl-Lphenylalanine ethyl ester (APEE, purity >99\%) was obtained from Bachem California Inc. (Torrance, $\mathrm{CA}$ ). $\mathrm{KH}_{2} \mathrm{PO}_{4}$ (purity $>99 \%$ ), hexane (optima grade, purity $>99.9 \%$ ) and anhydrous 1propanol (purity >99.9\%) were purchased from Fisher Scientific (Pittsburgh, PA) and were of the highest grade commercially available. The solvents were stored over oven-dried $3 \AA$ molecular sieves (4-8 mesh beads, Fisher Scientific) for at least $24 \mathrm{~h}$ prior to use. The enzyme preparations were prepared and stored in $15 \mathrm{~mL}$ flat-bottom glass vials that were closed with Teflon-lined screw caps after lyophilization. Activity assays were performed in $15 \mathrm{~mL}$ Teflon screw capped round bottom test tubes. All glassware was low-extractable borosilicate glass (Fisher-Scientific).

\section{Analytical}

To determine the amount of the enzymatically synthesized $N$-acetyl- $L$-phenylalanine propyl ester (APPE), $400 \mu \mathrm{L}$ aliquots of the homogeneous reaction mixtures were taken and spun at 3300 rpm for 30 seconds in Eppendorf tubes using a microcentrifuge. The supernatant was then analyzed via gas chromatography (GC, $1 \mu \mathrm{L}$ sample, Varian Model 3800, Varian Analytical Instruments, Sugar Land, TX; DB-5 capillary column, $30 \mathrm{~m}$ length, $0.25 \mathrm{~mm}$ I.D., $0.25 \mu \mathrm{m}$ film 
thickness; J\&W Scientific Inc., Folsom, CA, helium carrier gas flow $1.3 \mathrm{~mL} / \mathrm{min}$, split ratio $1 / 400$, injection and detection at $250^{\circ} \mathrm{C}$, linear column temperature ramp $150-210^{\circ} \mathrm{C}$ at $8^{\circ} \mathrm{C} / \mathrm{min}$ ). The water content of organic solutions ( $2 \mathrm{~mL}$ sample size) was measured by coulometric Karl Fischer titration (Denver Model 275KF titration module, Model 270 controller, Denver Instrument, Denver, CO). Hydranal Water Standard 0.10 (Riedel-de Haën, 100 mg water/g) was used to check the accuracy and reproducibility of the Karl Fischer titration.

\section{Procedure to prepare enzyme preparations}

Enzyme masses were determined by weighing the as-received enzyme. SC was diluted by shaking in a $10 \mathrm{mM}$ potassium phosphate buffer at $\mathrm{pH} 7.8$ (at room temperature) so that enzyme concentrations of $0.1 \mathrm{mg} / \mathrm{mL}$ to $6.67 \mathrm{mg} / \mathrm{mL}$ were achieved. As-received fumed silica was added to reach 0 to $98.5 \mathrm{wt} \%$ of silica relative to the final enzyme preparation mass. The aqueous preparations were sonicated for 10 minutes in a water bath to form homogeneous suspensions. A $3 \mathrm{~mL}$ aliquot per sample was then frozen in a $15 \mathrm{~mL}$ glass vial by immersing in liquid nitrogen for 20 minutes. This step was later replaced by placing the sample in a refrigerator at $-20^{\circ} \mathrm{C}$ (see below). The enzyme preparations were lyophilized for $72 \mathrm{~h}$ ( $48 \mathrm{~h}$ of primary drying, $24 \mathrm{~h}$ of secondary drying, VirTis model 10-MR-TR; Gardiner, NY) at a condenser temperature of $-50^{\circ} \mathrm{C}$ and a shelf temperature of $25^{\circ} \mathrm{C}$. The preparations were stored in screw capped glass vials at $20^{\circ} \mathrm{C}$.

\section{Kinetic Measurements}

The kinetic constants $v_{\max }$ and $K_{m}$ for the enzyme preparations were determined in nearly anhydrous hexane containing $8.3+/-3.1 \mathrm{ppm}(\mathrm{w} / \mathrm{w}) \mathrm{H}_{2} \mathrm{O}$ as determined by Karl-Fischer titration. The method for enzyme activation by adding inorganic salts prior to lyophilization [1] was reproduced for reference. Our data and the data from reference [1] are shown in Table 1 for 
comparison. Considering variability in the enzyme preparation and the overall methods we were able to reproduce the literature values reasonably well.

The model reaction was the transesterification reaction of $N$-acetyl- $L$-phenylalanine ethyl ester (APEE) with 1-propanol. This reaction was carried out as reported elsewhere [1].

$5 \mathrm{mg}$ of activated enzyme preparation were added to $5 \mathrm{~mL}$ of hexane containing 5-40 $\mathrm{m} M$ APEE, $0.85 M$ 1-propanol and $1.5 \mathrm{~m} M$ nonadecane as a non-reacting internal standard for GC analysis. The transesterification was carried out in $15 \mathrm{~mL}$ Teflon-lined screw capped glass vials constantly shaken in an incubator at $30^{\circ} \mathrm{C}$. Initial rate measurements were carried out over a period of $30-75$ minutes for additive-containing enzyme preparations (fumed silica or salt) and due to lower reaction rates for 90-270 minutes for additive free lyophilized SC. Initial rates were determined from linear fits over the average values of the GC measurements taken in duplicate. Kinetic parameters were calculated by fitting the obtained initial rate data to the Michaelis-Menten equation using Lineweaver-Burk plots. Figure 1 shows the good linearity of the LineweaverBurk plot for the model reaction (above) catalyzed by our SC preparation with $98.5 \mathrm{wt} \%$ fumed silica.

A reference experiment where no enzyme was added, but the fumed silica was included and processed identically to the enzyme activation experiments showed no measurable catalytic activity.

The final water content of the supernatant (spun for about 2 minutes at $3300 \mathrm{rpm}$ in a centrifuge) after completing the assay was determined by Karl Fischer titration to range between $257 \mathrm{ppm}$ and $318 \mathrm{ppm}(\mathrm{w} / \mathrm{w})$ depending on the added substrate concentration. This increase in water content compared to the initial water content in hexane is mainly due to the addition of water with the 1-propanol and the enzyme preparation. 


\section{Results and Discussion}

Figure 2 shows the enormous enhancement of the transesterification activity (represented by the initial reaction rate) of lyophilized SC in hexane as a function of the fumed silica content of the catalyst preparation. A sharp increase in activity was observed as the fumed silica content reaches up to $98.5 \mathrm{wt} \%$. This strong activity increase at high relative amounts of additive (salt or, in our case, fumed silica) relative to the mass of preparation is similar to results for inorganic salts [18].

Figure 3 shows the effect that the addition of $98.5 \mathrm{wt} \%$ fumed silica has on the initial reaction rates at different substrate concentrations compared to a SC preparation containing $98 \mathrm{wt} \% \mathrm{KCl}$ and an additive free one (enzyme-only, lyophilized). Table 1 shows that the observed maximum velocity $v_{\max }$ as well as the catalytic efficiency $v_{\max } / K_{m}$ (the activity of the catalyst at limiting substrate concentrations) for the $98.5 \mathrm{wt} \%$ fumed silica containing preparation (pre-frozen in $\mathrm{LN}_{2}$ ) was about 130 fold higher when comparing to enzyme only. Compared to $\mathrm{KCl}$-activation [1] our $v_{\max }$ is still twice as high whereas the catalytic efficiency shows an increase of about 1.5 fold over salt activation. While the value of $K_{m}$ stayed nearly constant the increase in catalytic efficiency appeared mainly due to the enhanced maximum velocity. Also shown in Table 1 is an experiment where we replaced the $\mathrm{LN}_{2}$ pre-freezing step for our fumed silica activation procedure by simple shelf-freezing in a refrigerator at $-20^{\circ} \mathrm{C}$. The results show that the efficiency can be further increased due to the lowered $K_{m}$ whereas $v_{\max }$ remained nearly constant.

While SC with an isoelectric point of $\mathrm{pH} 9.8$ possesses a positive net surface charge in the buffer ( $\mathrm{pH}$ 7.8) from which it was lyophilized, fumed silica has a negative surface charge at this $\mathrm{pH}$. This surface charge likely aids in non-covalent immobilization.

The presence of fumed silica or $\mathrm{KCl}$ influences the physical result of lyophilization. Figure 3A shows a scanning electron micrograph (SEM) of SC which has been lyophilized in the absence 
of FS or $\mathrm{KCl}$. Figure 3A can be compared to environmental SEM pictures for lyophilized subtilisin [24]. The structures shown in [24] show some resemblance to our sheet-like structures (Figure 3A). A direct comparison may be complicated by possible differences in the lyophilization procedure. The concern for mass transfer limitations in pure lyophilized enzyme powder is expressed in [24] and our work supports this concern.

After our lyophilization process the additive-free enzyme is present in the form of sheets, some of which have thicknesses on the order of micrometers. If this preparation were used in water the sheets would likely dissolve allowing each enzyme molecule to catalyze the desired reaction. Yet, when used in hexane, the enzyme will not dissolve. In hexane the enzyme molecules in the interior of the sheets seen in Figure 3A are essentially useless for catalysis.

In contrast, when the lyophilization takes place in presence of a significant amount of FS, the resulting particles are much smaller. As shown in Figure 3B, the particle sizes are now on the order of $1 / 100$ th of a micrometer or smaller. This is consistent with the size of individual "native" FS particles (native diameter about 7-50 nanometers). We hypothesize that the resulting preparation consists of non-porous FS particles with enzyme deposited on the surface. The thickness of the enzyme layer is dependent on the ratio of mass of enzyme to the available surface area of FS.

For comparison, an image of enzyme lyophilized in the presence of $\mathrm{KCl}$ is shown in Figure 3C. Salt crystals of sub-micrometer dimensions are evident. The differences in the geometry and specific surface area (surface area per mass) of salt crystals and FS may play an important role in determining the apparent catalytic activity per mass of enzyme.

We hypothesize that mass transfer limitations are the major obstacle to high activity of the pure $\mathrm{SC}$ in hexane. If this is true, any preparation procedure that produces well dispersed enzymes in 
hexane will have a higher activity than the enzyme alone. Below we will show experimental evidence to support this hypothesis.

Figure 5 shows schematically how enzyme molecules may interact with the fumed silica surface. We shall assume that only enzyme molecules that are directly exposed to solution contribute significantly to the enzyme activity that is detected. This assumption is supported by the very low activity of pure lyophilized enzyme in hexane, where thick sheets of enzyme only allow few enzyme molecules to have relatively unimpeded access to substrate. Figure 4 shows schematically why one observes increased enzyme activity (per mass of enzyme) as more and more FS area is made available for immobilization of the enzyme. As seen in this Figure, when a large ratio of enzyme to non-porous substrate (FS) is employed, the enzyme is deposited in multiple layers. Only the uppermost layer is freely accessible for catalysis. As the ratio of nonporous substrate to enzyme is increased the thickness of the enzyme layer is reduced until it reaches the monolayer level. Upon further increase in the support-to-enzyme ratio a submonolayer coverage is reached with individual enzyme molecules highly dispersed and available for catalysis. We shall first calculate significant parameters and then examine experimental evidence to support this view.

According to this model the catalytic activity of an enzyme preparation (enzyme immobilized on support) should increase when the relative amount of enzyme per available surface area is increased. When a monolayer of enzyme on the carrier surface has been reached further addition of enzyme to the preparation may result in no significant further increase of activity of the preparation. For fumed silica the specific surface area $F_{s p e c(F S)}$ was given by the supplier as 258 $\mathrm{m}^{2} / \mathrm{g}_{\mathrm{FS}}$. The number $n_{S C}$ of subtilisin Carlsberg molecules needed to form a complete monolayer on the surface of fumed silica can be estimated using the area $f_{S C}$ that one molecule of SC 
requires on the surface of FS (eq. 1). The following calculation assumes the area required for adsorption of an individual SC molecule to be approximately $f_{S C}=20 \mathrm{~nm}^{2}$. This estimate is based on a correlation of molecular weight and radius [25] with added area to account for packing of "hard" spherical molecules on a plane.

$$
n_{S C}=\frac{F_{s p e c(F S)}}{f_{S C}} \approx 1.3 \cdot 10^{19} / g_{F S}
$$

The ratio of the mass of FS $m_{F S}$ to the mass of subtilisin Carlsberg $m_{S C}$ needed to form a dense monolayer on the surface of fumed silica is then

$$
\frac{m_{F S}}{m_{S C}}=\frac{m_{F S}}{\left(\frac{M W_{S C}}{N_{A v}}\right) \cdot n_{S C} \cdot m_{F S}} \approx 1.72 \frac{g_{F S}}{g_{S C}}
$$

where $\mathrm{N}_{\mathrm{Av}}$ is Avogadro's constant and $\mathrm{MW}_{\mathrm{SC}}$ is the molar mass of SC which was assumed to be $27000 \mathrm{~g} / \mathrm{mol}$. Figure 6 shows that the experimentally determined catalytic activities for SC preparations still increase far above the estimated monolayer value of $\mathrm{m}_{\mathrm{FS}} / \mathrm{m}_{\mathrm{SC}}$ of 1.72 . Reasons may include that the surface area of FS actually available for enzyme immobilization is less than the area reported by the manufacturer, and that the optimum monolayer packing density for fully accessible and active enzyme molecules may be less than the perfect coverage assumed above. We hypothesize that the intersection of the trend lines in Figure $5\left(\mathrm{~m}_{\mathrm{FS}} / \mathrm{m}_{\mathrm{SC}} 23\right)$ indicates where a further increase of the relative amount of mass (or available area) of FS available to the enzyme does not contribute strongly to increase enzymatic activity since the available area is already nearly sufficient for all enzyme molecules to be easily accessible to the solution. 
These results can be checked against the specific catalytic activities (catalytic activity normalized by mass of final enzyme preparation) in hexane for the different enzyme preparations. Since an increase in the amount of FS in the preparation is only effective (in respect to the catalytic activity) until every enzyme molecule is finally accessible, a maximum should occur at about 96 wt\% FS according to the considerations above (Figure 5). The enzyme preparation containing 95 wt\% FS shows the highest specific catalytic activity. Substrate conversions after 60 min for the different FS containing enzyme preparations at an initial substrate concentration of $5 \mathrm{mM}$ also reach the maximum of $25.0 \%$ at $95 \mathrm{wt} \% \mathrm{FS}$.

To provide additional support for our hypothesis that an increased availability (and activity) of enzyme molecules is achieved by dispersing them on a non-porous support another support was tested. An inorganic hydrophilic material (Aeroxide ${ }^{\circledR}$ Alu C) was employed to investigate if material-specific effects could be detected for the observed activation. Aeroxide ${ }^{\circledR}$ Alu $\mathrm{C}$ is a highly dispersed fumed aluminum oxide with a nominal specific surface area of $100+/-15 \mathrm{~m}^{2} / \mathrm{g}$ (about 1/2 the value of FS). The enzyme preparation was prepared as described above for fumed silica. A final weight ratio of Aeroxide ${ }^{\circledR}$ Alu C of $98.5 \%$ with pre-freezing for 20 min in $\mathrm{LN}_{2}$ was prepared. Since $K_{m}$ remained nearly constant when compared to the equivalent FS preparation (Table 1), the 1.5 fold increase in catalytic efficiency can be ascribed to the increase in $v_{\max }$ of about $60 \%$. This further supports our hypothesis that the activation of enzymes in organic media observed here is due mainly to improved mass transfer and is largely independent of the support material.

Finally, our results achieved here using $\mathrm{KCl}$ and reported in Table 1 appear to be consistent with our surface area hypothesis. Ru et al. [1] have suggested that the enhanced activity for the enzyme/salt preparations is mainly the result of subtle interactions between salt and enzyme prior 
to and after lyophilization. While these interactions may contribute to the properties of saltcontaining preparations, the simpler explanation of reduced mass transfer limitations by dispersing the enzyme molecules on a surface at or below monolayer coverage appears to be the dominant effect.

It was reported that the salt activation method showed the best results when the mixtures were pre-frozen most rapidly in $\mathrm{LN}_{2}$ [1]. It is well known that more rapid cooling of solutions of inorganic salts will generally produce smaller salt crystals. The results for $\mathrm{LN}_{2}$ pre-freezing of salt-containing enzyme solutions therefore seem to support our hypothesis that an increased surface area available for enzyme immobilization is to a large part responsible for increased enzyme activity.

\section{Conclusions}

SC can be highly activated in organic solvents by lyophilization in the presence of fumed silica and fumed aluminum oxide. The activation reaches and sometimes exceeds that reported using inorganic salts as additives before lyophilization. The amount of fumed silica needed can be related to the surface area needed for formation of an enzyme monolayer. Once enzyme multilayers are formed any additional enzyme appears not well utilized for catalysis. Our work shows strong evidence that mass transfer limitations are one main obstacle to the efficient use of enzymes in organic solvents. Specific interactions of soluble salts with enzymes are not needed to produce activated SC preparations for use in hexane. The availability of easily produced and inexpensive highly active enzyme preparations for use in organic solvents may advance applications such as the production of specialty polymers and optically active specialty chemicals and pharmaceuticals [2]. 


\section{Acknowledgements}

K.W. thanks the InWEnt GmbH, Germany for a fellowship. The support to P. H. P. by the

Cargill Fellowship in Bioprocessing in the College of Engineering at Kansas State University is gratefully acknowledged.

\section{References}

[1] M.T. Ru, K.C. Wu, J.P. Lindsay, J.S. Dordick, J.A. Reimer, D.S. Clark, Biotechnol. Bioeng. 75 (2001) 187.

[2] A.M. Klibanov, Nature 409 (2001) 241.

[3] A. Zaks, A.M. Klibanov, Proc. Natl. Acad. Sci. USA 82 (1985) 3192.

[4] A.M. Klibanov, Chemtech 16 (1986) 354.

[5] A. Zaks, A.M. Klibanov, Science 224 (1984) 1249.

[6] A. Zaks, A.M. Klibanov, J. Am. Chem. Soc. 108 (1986) 2767.

[7] M. Quiros, V.M. Sanchez, R. Brieva, F. Rebolledo, V. Gotor, Tetrahedron: Asymmetry 4 (1993) 1105.

[8] J.S. Dordick, Enzyme. Microb. Technol. 11 (1989) 194.

[9] D.H. Altreuter, D.S. Clark, Curr. Opin. Biotechnol. 10 (1999) 130.

[10] D. Bratko, A. Luzar, S.H. Chen, J. Chem. Phys. 89 (1988) 545.

[11] M. Persson, E. Wehtje, P. Adlercreutz, Chembiochem 3 (2002) 566.

[12] T. Maruyama, T. Kotani, H. Yamamura, N. Kamiya, M. Goto, Org. Biomol. Chem 2 (2004) 524.

[13] T. Itoh, S. Han, Y. Matsushita, S. Hayase, Green Chemistry 6 (2004) 437.

[14] J.K. Lee, M.-J. Kim, J. Org. Chem. 67 (2002) 6845.

[15] T. Sakai, K. Hayashi, F. Yano, M. Takami, M. Ino, T. Korenaga, T. Ema, Bull. Chem. Soc. Jpn. (2003) 1441.

[16] S. Ueji, S. Mori, H. Yumoto, N. Hiroshima, Y. Ebara, Chem. Lett. 34 (2005) 110. 
[17] M.T. Ru, S.Y. Hirokane, A.S. Lo, J.S. Dordick, J.A. Reimer, D.S. Clark, J. Am. Chem. Soc. 122 (2000) 1565.

[18] Y.L. Khmelnitsky, S.H. Welch, D.S. Clark, J.S. Dordick, J. Am. Chem. Soc. 116 (1994) 2647.

[19] Lindsay, J. P., D.S. Clark, J.S. Dordick, Biotechnol. Bioeng. 85 (2004) 553.

[20] A. Zaks, A.M. Klibanov, J. Biol. Chem. 263 (1988) 8017.

[21] G. Carrera, S. Riva, Angew. Chem. 39 (2000) 2226.

[22] S. Toba, D.S. Hartsough, K.M.J. Merz, J. Am. Chem. Soc. 118 (1996) 6490.

[23] J.P. Lindsay, D.S. Clark, J.S. Dordick, Enzyme. Microb. Technol. 31 (2002) 193.

[24] K. Roziewski, A.J. Russell, Biotechnol. Bioeng. 39 (1992) 1171.

[25] R. Schnabel, P. Langer, S. Breitenbach, J. Membr. Sci. 36 (1988) 55. 


\section{Tables}

Table 1. Effect of $98.5 \mathrm{wt} \%$ fumed silica and $98.5 \mathrm{wt} \%$ Aeroxide ${ }^{\circledR} \mathrm{Alu} \mathrm{C}$ as an additive during lyophilization of $\mathrm{SC}$ (preparations pre-frozen in $\mathrm{LN}_{2}$ or shelf-frozen at $-20^{\circ} \mathrm{C}$ as indicated) compared with $\mathrm{KCl}$ activation data from [1] and reproduced by us, and an additive free preparation.

\begin{tabular}{|c|c|c|c|}
\hline Additive & $\begin{array}{c}v_{\max } \\
\left(\mu \mathrm{mol}_{\mathrm{APEE}} \min ^{-1} \mathrm{mg}_{\text {enz }}\right)\end{array}$ & $\begin{array}{c}K_{m} \\
(\mathbf{m} M) \\
\end{array}$ & $\begin{array}{l}\text { catalytic efficiency } v_{\max } / K_{m} \\
\left(\mu \mathrm{mol}_{\mathrm{APEE}} \mathrm{min}^{-1} \mathrm{mg}^{-1}{ }_{\mathrm{enz}} \mathrm{m} M^{-1}\right)\end{array}$ \\
\hline $\begin{array}{l}98.5 \mathrm{wt} \% \text { fumed silica } \\
\text { (preparation pre-frozen } \mathrm{LN}_{2} \text { ) }\end{array}$ & 341.7 & 9.5 & 35.9 \\
\hline $\begin{array}{l}98.5 \mathrm{wt} \% \text { fumed silica } \\
\text { (preparation pre-frozen at }-20^{\circ} \mathrm{C} \text { ) }\end{array}$ & 317.9 & 3.3 & 96.8 \\
\hline $\begin{array}{l}98.5 \mathrm{wt} \% \text { Aeroxide }{ }^{\circledR} \text { Alu C } \\
\text { (preparation pre-frozen in } \mathrm{LN}_{2} \text { ) }\end{array}$ & 559.2 & 10.2 & 54.9 \\
\hline $\begin{array}{l}98 \mathrm{wt} \% \mathrm{KCl} \text { our data, } \\
\text { method see [1] }\end{array}$ & 122 & 2.2 & 56.5 \\
\hline $98 \mathrm{wt} \% \mathrm{KCl}[1]$ & 175 & 7.0 & 24.9 \\
\hline none, enzyme only & 2.6 & 9.1 & 0.28 \\
\hline
\end{tabular}




\section{Figures}

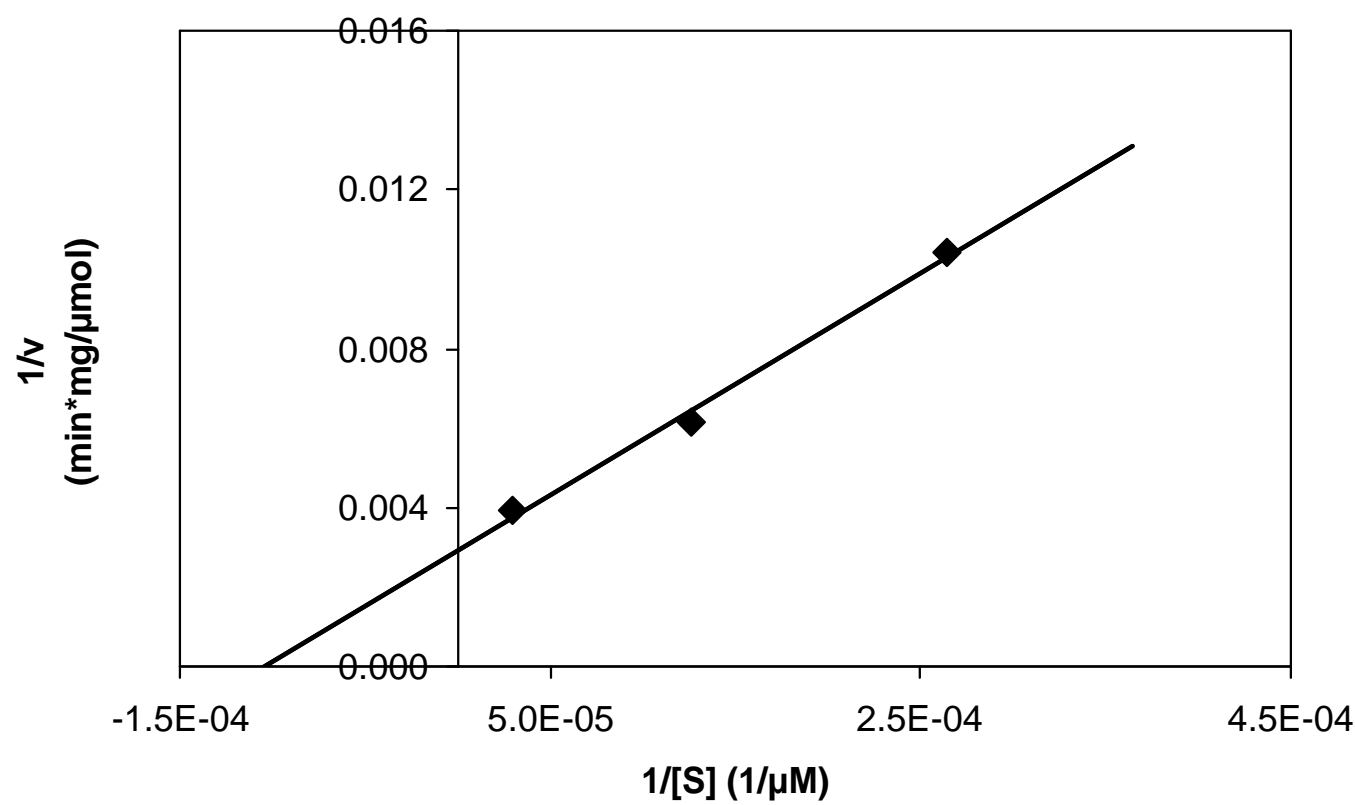

Figure 1. Lineweaver-Burk plot for reaction rate data of our SC preparation containing $98.5 \mathrm{wt} \%$ fumed silica. 


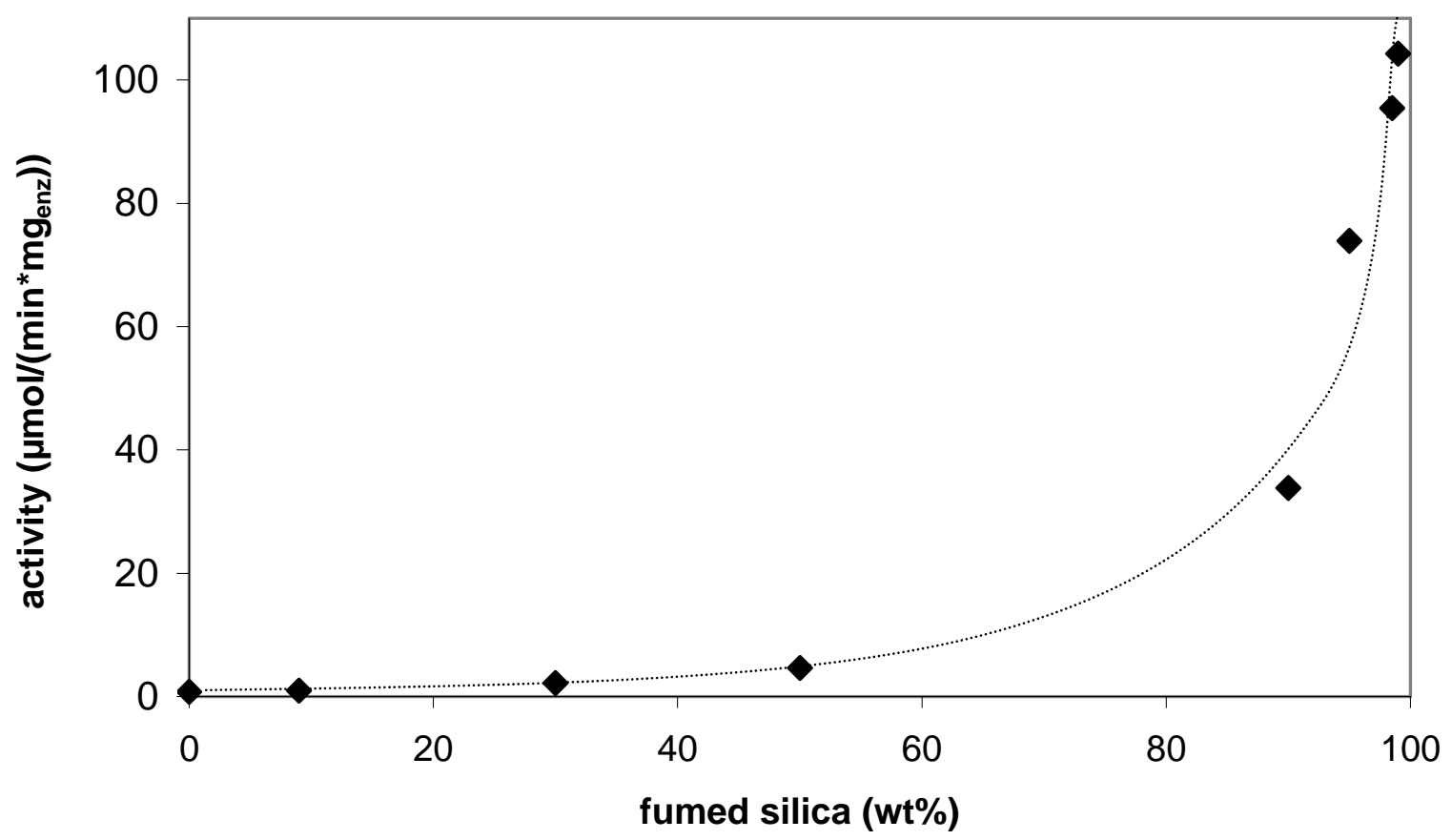

Figure 2. Catalytic activity of SC in nearly anhydrous hexane as a function of the fumed silica content in the freeze-dried enzyme preparation at substrate concentrations of $5 \mathrm{~m} M$ APEE. Significant activation is achieved at high fumed silica content relative to the final preparation mass. The line was added to aid visual interpretation. 


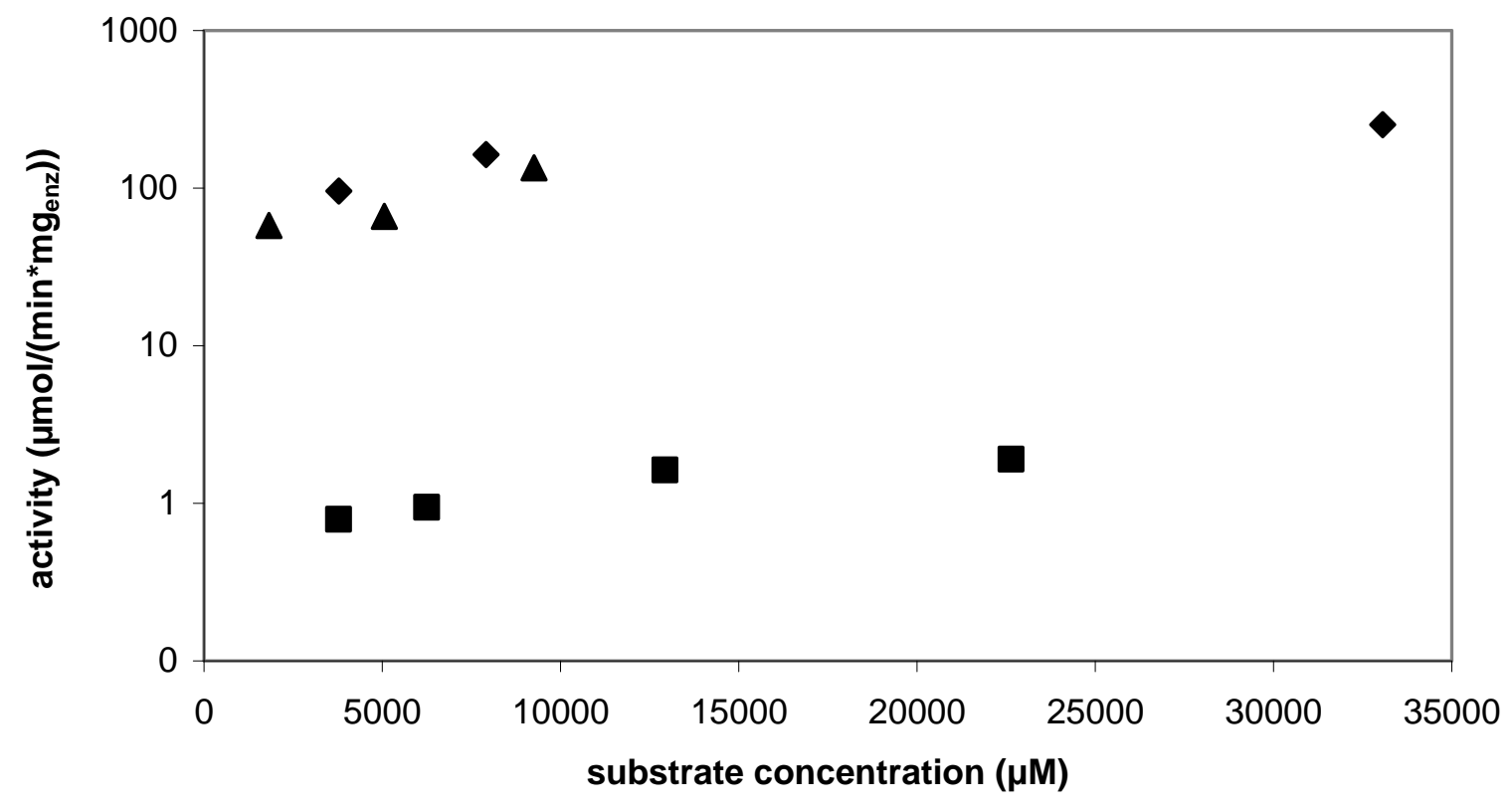

Figure 3. Comparison of catalytic activities of enzyme-only SC preparation ( $\mathbf{\square})$, SC preparation containing $98 \mathrm{wt} \% \mathrm{KCl}(\boldsymbol{\Delta}$, own data) and SC preparation containing $98.5 \mathrm{wt} \%$ fumed silica $(\diamond)$ in nearly anhydrous hexane at different APEE concentrations. Supporting the enzyme on either fumed silica or salt crystals results in an increase in reaction rate of approximately two orders of magnitude. 

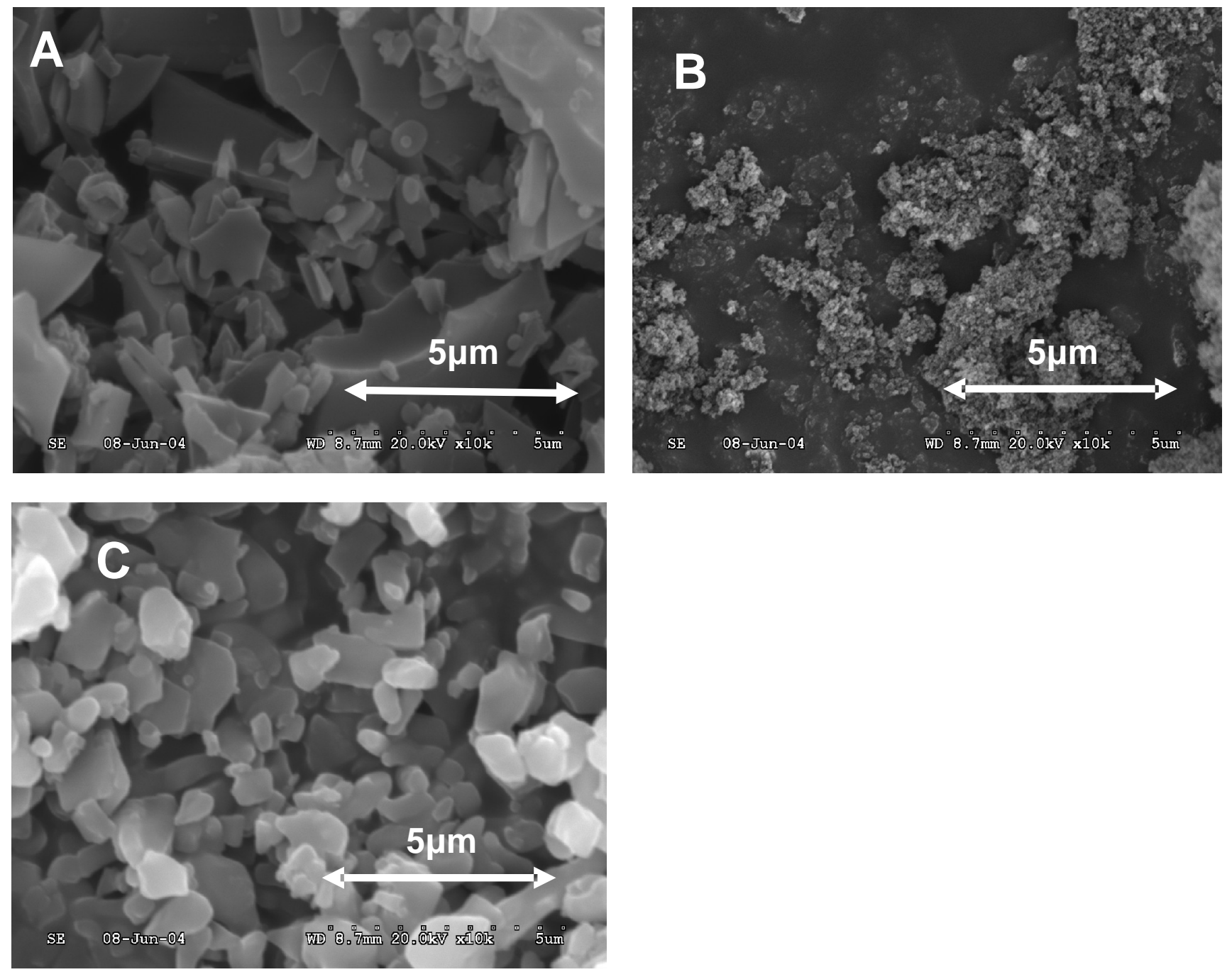

Figure 4. Scanning electron micrographs (SEM) of lyophilized SC with and without added fumed silica or $\mathrm{KCl}$.

A: enzyme only

B: $98.5 \mathrm{wt} \%$ fumed silica added to the aqueous buffer solution prior to lyophilization

C: $98 \mathrm{wt} \% \mathrm{KCl}$ added to the aqueous solution prior to lyophilization ( $\mathrm{LN}_{2}$ pre-freezing)

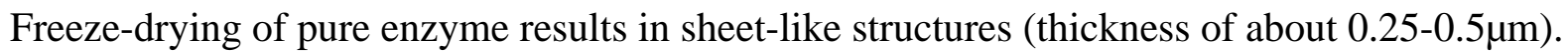
This points towards possible mass transfer limitations compared to the finely divided SC on the surface of FS or salt crystals $(\mathbf{B}, \mathbf{C})$. 

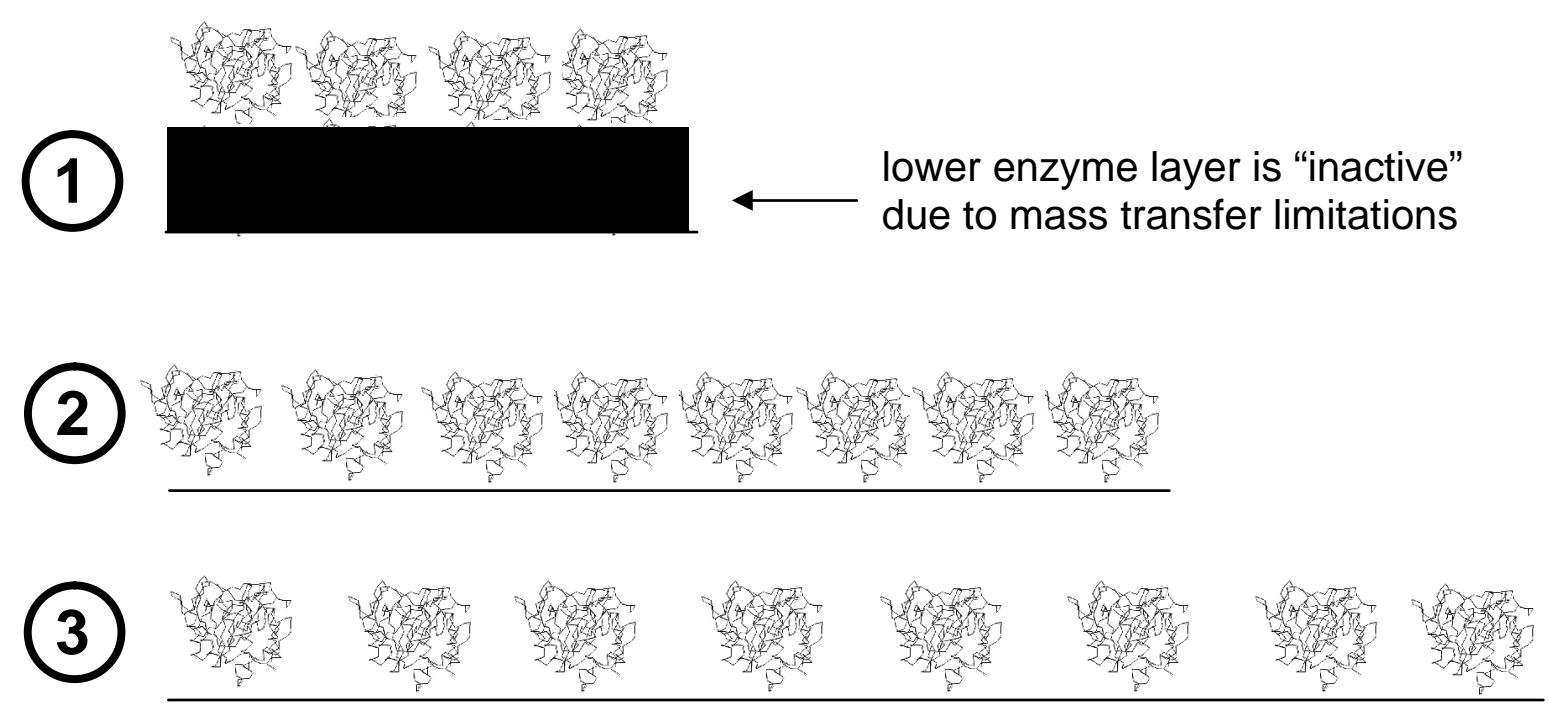

Figure 5. Three possible stages of enzyme adsorption to the surface of fumed silica:

(1) multilayer; (2) monolayer; (3) thinned-out monolayer. 


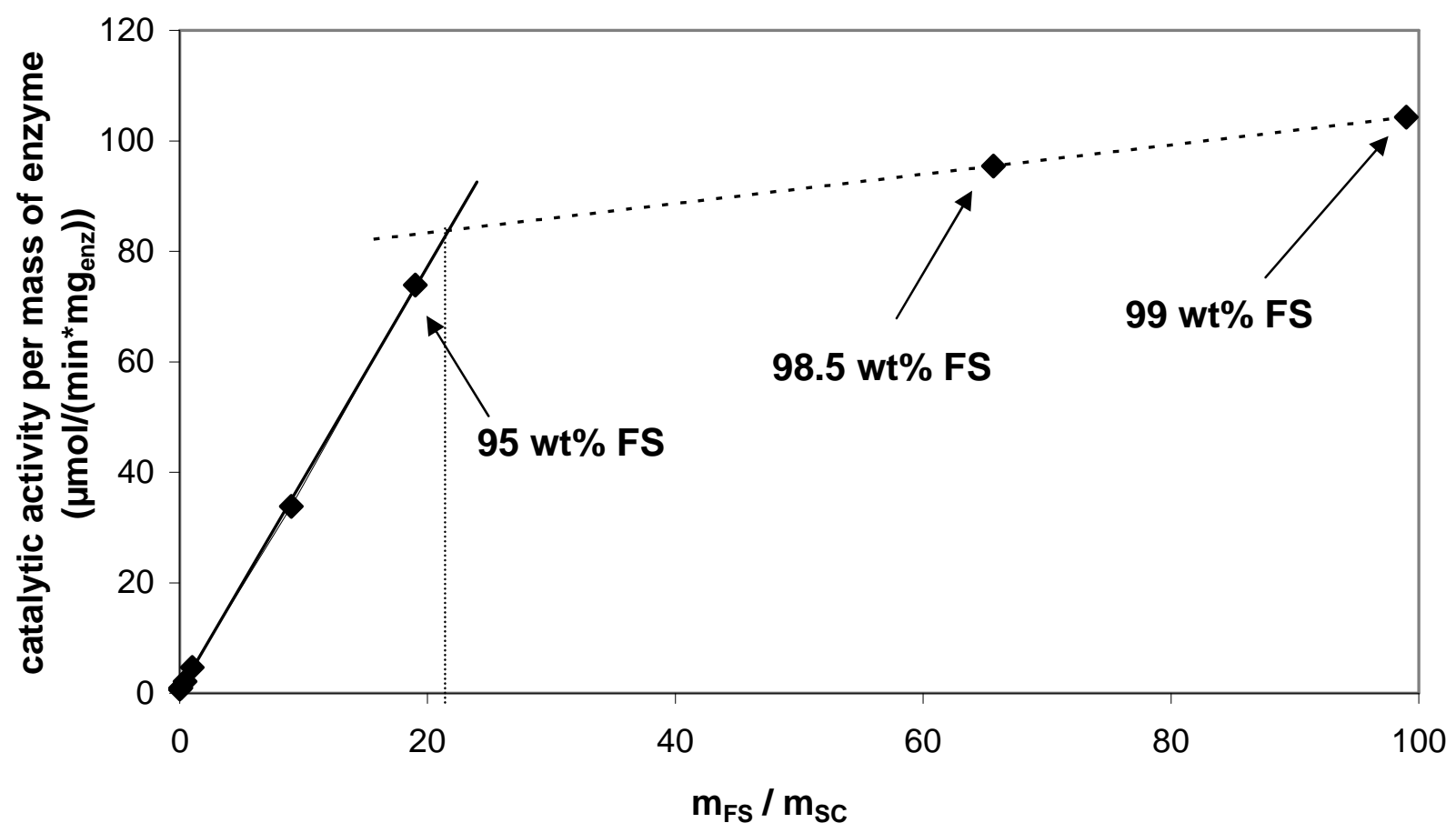

Figure 6. A linear relationship is found between the catalytic activity per mass of enzyme and the mass of FS available per mass of $\mathrm{SC}$ up to $\mathrm{m}_{\mathrm{FS}} / \mathrm{m}_{\mathrm{SC}} \sim 23$. Additional area available for $\mathrm{SC}$ adsorption beyond $\mathrm{m}_{\mathrm{FS}} / \mathrm{m}_{\mathrm{SC}} \sim 23$ does not increase the catalytic activity per mass of enzyme since the available area begins to exceed the needed area for all enzyme molecules to be easily accessible. 